Max-Planck-Institut für demografische Forschung

Max Planck Institute for Demographic Research

Doberaner Strasse $114 \cdot$ D-18057 Rostock · GERMANY

Tel +49 (0) 3812081 - 0; Fax +49 (0) 3812081 - 202;

http://www.demogr.mpg.de

MPIDR WORKING PAPER WP 2002-031

JULY 2002

Patterns of twinning

for Swedish women, 1961-1999

Margit Strandberg (margit.strandberg@ telia.com)

Jan M. Hoem (hoem@ demogr.mpg.de)

(C) Copyright is held by the authors.

Working papers of the Max Planck Institute for Demographic Research receive only limited review.

Views or opinions expressed in working papers are attributable to the authors and do not necessarily reflect those of the Institute. 
MS/JMH, 24 January 2002

\title{
Patterns of twinning for Swedish women, 1961-1999
}

\author{
by Margit Strandberg ${ }^{1}$ and Jan M. Hoem ${ }^{2}$
}

\begin{abstract}
The Nordic population registers provide a unique possibility to study the demographic behavior of small population groups and rare events. In this paper, we study the childbearing behavior of Swedish mothers of twins between 1961 and 1999, inclusive. The twinning rate has increased since the mid-1970s in response to a growing use of fertility-stimulating treatments such as in-vitro fertilization. Such medical procedures are applied mainly to women beyond prime childbearing ages. Nevertheless, we find no simple age pattern in twinning rates. They do not just increase with the woman's age. Our most consistent finding is that mothers of twins wait noticeably longer than women with singletons before they have another child. This apart, mothers with twins at their first birth have next-birth fertility patterns very similar to women who have two singletons at their first two births. This commonality in childbearing behavior does not extend to higher-order births, though. For mothers with a singleton and a pair of twins, the progression to a third birth depends very much on whether the twins came first or second. We also discover that at parities beyond 3, twinning rates increase with parity, especially at very short durations since the previous birth.
\end{abstract}

\section{Content}

Page

1. Introduction

2. Historical trends

3. Twinning at first birth

4. Mothers of a pair of twins and mothers of one singleton 4

5. Mothers of a pair of twins and mothers of two singletons 5

6. The third birth to mothers of twins 5

7. Twinning at positive parities 6

8. Operational conclusions 7

$\begin{array}{ll}\text { References } & 7\end{array}$

Tables 9

$\begin{array}{ll}\text { Diagrams } & 16\end{array}$

\footnotetext{
${ }^{1}$ Valhallavägen 12 B, S-114 22 Stockholm, margit.strandberg@telia.com.

${ }^{2}$ Max Planck Institute for Demographic Research, Doberaner Straße 114, D-18057 Rostock, hoem@demogr.mpg.de.
} 


\section{Introduction}

While the literature is rich in studies of twins, very little seems to be known about the demographic behavior of the parents of twins. Demographers suspect that these parents have patterns of childbearing and family dynamics that differ from others and therefore frequently censor life histories at the arrival of twins, but empirical investigations have only just begun to appear. Since twinning is a relatively rare event, special types of data sets are needed, preferably extensive databases like the Nordic population registers. The advantage of the wall-to-wall coverage given by these national population registers is that they allow us to map patterns of the demographic behavior even of very small groups and very rare events. In parallel with Walke's simultaneous investigation of divorce risks for parents of twins (Walke, 2001), we tap this exciting data source for information about the childbearing behavior of mothers of twins.

Most of our report contains a comparison between mothers of twins and mothers of one or two singletons. Our main findings are as follows:

The second-birth fertility of women whose first birth resulted in twins is much lower than for corresponding mothers with singleton first births; in fact, the childbearing intensity of the former has diminished from some forty-five per cent of the latter in the 1960s to some twenty-five per cent or so in the 1990s. During our forty-year period of observation, the second-birth fertility of the same twin mothers remained roughly at the same level as the third-birth fertility of mothers of two singletons. Indeed, trends in the fertility of mothers of twins largely follow those for mothers of singletons. We also display some patterns by the age of the mother and of the first child or twins. The main analysis is put into perspective by a brief preceding account of trends in twin births in Sweden.

\section{Historical trends}

The fraction of births that were twin births was very stable at 14 per 1000 total births each year for more than fifty years after 1870 (Figure 1). It then declined gradually to about 8 per 1000 in the 1970s, whereafter it rapidly rose to almost twice that level by the end of the twentieth century, surely mainly as a consequence of medical fertility-stimulating measures used to help childless women. Such an increase was also reflected in the number of children born. In the 1970s, some 1800 twins were born in Sweden each year; two decades later, there were about 3000. The number of triplet births was as low as some ten per year during the 1960s and 1970s. In the 1980s, it increased to about thirty per year and reached a record high of sixty in 1993. By the end of the 1990s, the number of triplet births had declined again to around twenty. During the late 1980s and early 1990s, Sweden had an occasional quadruplet birth.

Eriksson and Fellman (1967a, 1967b, 1973) have analyzed early twinning trends in the Nordic countries. During the nineteenth early twentieth century, Nordic twinning rates were among the highest in the world. The authors found particularly high rates in isolated population groups where a high level of intermarriage was recorded. When migration increased and the mean age at childbearing decreased, the twinning rates declined. They were regarded as being correlated with the mother's age at childbearing (Eriksson and Fellman, 1973) or parity (Pollard, 1969; Högberg and Wall, 1992). Recent Swedish statistics also show that the mean age at twin births is 
one to one-and-a-half year higher than that of singleton births (Figure 2). ${ }^{3}$ However, the twinning rate is particularly high for women in their thirties and it falls at higher ages (Figures $3 \mathrm{a}$ and $3 \mathrm{~b}$ ). We cannot find any simple relation between twinning and age.

Figure 4 shows that the Swedish twinning rate increased considerably in the last three-quarters of the twentieth century even when one controls for the changing age distribution among mothers. Evidently, new features have entered into the picture. Lundin (1996) pinpointed in-vitro fertilizations as a main factor in this development. ${ }^{4}$ Such treatment is normally administered to women of a relatively high age and only after they have undergone long periods of tests. This treatment alone would contribute to a relatively high age at twin birth.

\section{Twinning at first birth}

Since 1961, Swedish fertility has gone through what Hoem and Hoem (1996) called a roller-coaster development. It can be depicted in various ways; in Figure 5 we show it in the form of a series of age-standardized annual indexes for singleton first births and a corresponding series for twin first births, using the level in 1990 as a baseline for each curve separately. We see that the two series run largely parallel until the early 1980s, after which the series for twin births has its own upward impetus. If we turn to relative risks, we find that the twin-birth "risk" of a childless Swedish woman was some 0.6 to 0.7 per cent of the corresponding singleton-birth intensity during the first two decades after 1961, but the relation then changed and the relative risk increased to almost two per cent by the end of the 1990 s. $^{5}$ This again reflects the increase in in-vitro fertilizations, which are used mainly for childless women. Figure 6 shows to what extent the age profile of twin births is shifted towards higher ages.

Figures 5 and 6 are based on Table 1, which contains maximum-likelihood estimates of the parameters of a competing-risks intensity model ${ }^{6}$ of the form $\mu_{k x}^{(h)}=\theta c_{k h} a_{x h},{ }^{7}$ where $x$ is the woman's current age group, $k$ represents the current calendar period, and $h$ is the multiplicity of the first birth; i.e.. $h=1$ or 2 ; we censor at births of multiplicity above 2 . To achieve identification, we have let $c_{k_{0} 1}=1$ for a suitable $k_{0}$ and $a_{x_{0}}=1$ for a suitable $x_{0}$. We estimate the general fertility level $\theta$ to be

${ }^{3}$ Figures 1 through 4 are based on population statistics in annual publications from Statistics Sweden. Figure 5 is the result of our own computations based on the Swedish population register, as are all subsequent diagrams and all tables in this paper. We have had the individual-level register data from 1961 through 1999 at our disposal. Our source data only included liveborn children; thus a twin birth where only one child was liveborn is counted as a singleton birth. Each woman's record is censored at her death or first emigration after first birth and at the end of 1999.

${ }^{4}$ The first children born in Sweden after in-vitro fertilization were delivered in 1982 (Socialstyrelsen, 1998).

${ }^{5}$ See the last column of Panel 1 in Table 1.

${ }^{6}$ See Hoem (1987) for a general theory of such simple multiplicative intensity models.

${ }^{7}$ In this model, the birth multiplicity is included in interaction with both covariates at the same time. Our reasoning is based on this model. Because it has been much more practical for us, we have fitted the simpler model $\mu_{k x}^{(h)}=\theta c_{k h} a_{x}$ and have got the results in the first panel in Table 1, and $\mu_{k x}^{(h)}=\theta c_{k} a_{h x}$ to get the figures in the second panel, i.e., we have operated with one "interaction" with the birth multiplicity at a time. For our purpose, this is a sufficiently accurate approximation. A corresponding comment pertains to all parameter estimates in our tables and diagrams. 
5.3 per 10000 person-months of exposure. Across all ages and periods, the rate of arrival of twin births is 0.0093 relative to the rate of singleton births. ${ }^{8}$

\section{Mothers of twins and mothers of one singleton}

We now turn to our main topic, namely the fertility of mothers of twins. In our analysis we estimate simultaneously two competing risks again, this time (i) the intensity of having a singleton second birth and (ii) the corresponding intensity for a twin second birth. As in Section 3, we use a standard multiplicative intensity model for each risk, now of the format $\mu_{i j k t}^{(h)}=\theta a_{i j} b_{j h} c_{k j} d_{t j}$. The index $h$ is used for the multiplicity of the second birth. Our covariates are (1) the woman's age group at first birth, indexed by $i,(2)$ the multiplicity of the first birth, now indexed by $j$, and (3) the current calendar period (regarded as a time-varying covariate), indexed by $k$ and grouped as in Table 3, which contains our maximum-likelihood estimates of most parameters and corresponding derivatives. Estimates of the relative risks $b_{j h}$ are given in Table 2. Our duration variable $t$ is time since first birth, grouped as also shown in Table 3. The analysis applies to women born in Sweden who have had a first birth of multiplicity 1 or 2 . (We have left out the few women who had first births of multiplicity above 2.) To ensure parameter identification, we have set $b_{11}=1$, precisely one of the $a_{i h}$ is also set to 1 , and so on. This means that the parameters represent relative risks.

We have found that across all ages, calendar periods, and both first-birth multiplicities, the rate of arrival of twin births is 0.342 relative to the rate of singleton births. ${ }^{9}$ This means that on average, mothers who delivered twins at their first birth have only about one-third as high an intensity for a second birth as mothers whose first confinement resulted in a single child. We have also found that $\hat{b}_{21}=0.338$ (Table 2). This is our estimate for the relative risk of having a singleton at the second birth when the mother had twins in her first delivery.

In addition, we estimate $\hat{b}_{12}=0.010$ and $\hat{b}_{22} / \hat{b}_{12}=0.022,{ }^{10}$ which means that if these women have a second birth, mothers whose first delivery resulted in twins have about twice as high a chance of giving birth to twins again as women whose first delivery resulted in a singleton. ${ }^{11}$ This may constitute further evidence that twin births run in families.

The first panel in Table 3 contains our estimates $\left\{\hat{c}_{k j}\right\}$ and some derivatives. It displays the trends in our second-birth intensities across calendar periods. In the first two columns, the intensities are given relative to the intensity for 1991-1993 for mothers who delivered a singleton at the first birth. In the next two columns, we provide the second-birth intensity for mothers with a twin first birth relative to the first-birth intensity for women who had a singleton first birth in the same period. In

\footnotetext{
${ }^{8}$ This is our maximum-likelihood estimate of the relative risk $m_{2}$ of having a twin birth in the first confinement based on the model $\mu_{k x}^{(h)}=\theta m_{h} c_{k} a_{x}$, with $m_{1}=1$. Note that this means that the figure 0.0093 has been standardized for period and age.

${ }^{9}$ This figure has been standardized for our three covariates. Compare with our previous footnote.

${ }^{10}$ The latter value is based on a computation using more decimals than those shown in Table 2.

${ }^{11}$ In our material, 122 mothers who delivered twins at their first birth also had twins at their second birth. The numbers are small but the size of our data set and the sensitivity of our method of analysis permits us to make interesting findings nevertheless.
} 
the last pair of columns, the second-birth intensities are given relative to the intensity for 1991-1993 for each first-birth outcome separately. The latter columns have been plotted in Figure 7, and we see that the intensities for a second birth largely have followed the same trends, irrespective of the outcome of the first birth. The most obvious deviations are the much stronger decline in second-birth intensities for mothers of twins between 1965 and 1975, and again after the early 1990s. Meanwhile, the characteristics of twin mothers as a group have changed. In the later period, a greater fraction of them consists of women who have had difficulties getting pregnant and who have had their twins after medical intervention.

In the second panel of Table 3 we display the effect of the age of the mother at first birth. The columns have been computed in a manner similar to that of the first panel, and the two last columns of this second panel have been plotted in Figure 8. Obviously, the relative intensity of a second birth among twin mothers is much higher among women who had their twins at a relatively young age, and this pattern is quite different from that of women who delivered a singleton at their first birth. The first columns in the second panel of Table 3 show that this does not mean that young twin mothers have particularly high intensities for a second birth. It is only relative to other twin mothers that those who had their twins early have high second-birth intensities.

The final panel in Table 3 and Figure 9 shows the extent to which the secondbirth intensity for mothers of twins and singletons depends on the duration since their first confinement. We see again that mothers of twins in general wait longer before they have another birth.

\section{$\underline{5 . \text { Mothers of a pair of twins and mothers of two singletons }}$}

Another interesting comparison is that of the next-birth intensity of a mother of twins and a comparable mother of two singletons. Both have two children, so in some sense we want to compare the intensities of women at parity 2 , taking into account the manner in which that parity was attained. Parameter estimates of an intensity model similar to the one in our previous section are given in Table 4. Let us start by noting that the two groups we now study largely have the same next-birth fertility, and that the trends of each group across calendar time are very close to each other (Figure 10). Twin mothers tend to wait longer before they venture into their next birth than mothers of two singletons do (Figure 11). This apart, the two groups have remarkably similar fertility.

\section{The third birth to mothers of twins}

We now turn to third births for women who previously have had twins either in their first or second delivery ${ }^{12}$ It turns out that there is a considerable difference in childbearing behavior between women whose twin birth came first and those whose twin birth came second (Table 5). All in all, the first group has had twice ${ }^{13}$ as high a third-birth intensity as the second, perhaps because at each stage after the second birth, the twins are older and the situation therefore more manageable than when the twins came in the second delivery.

According to Figure 12, the difference in third-birth intensities was smaller in the 1960s than thereafter. Since more women were housewives in our first period than

\footnotetext{
${ }^{12}$ In our data, no woman who had two twin births ever had a third birth. This does not merit a study of third births in this group.

${ }^{13}$ Our estimate of the relative risk is 1.982.
} 
in the later ones, we speculate that having a third birth was more manageable than later on even when one of the previous births had resulted in twins. The age of the mother does not seem to have much influence (Figure 13) ${ }^{14}$ By contrast, the age of the youngest child seems to be important, in that fertility differences between the two groups diminish as the child's age increases (Figure 14). Again, the age of the twins may be the driving element.

\section{Twinning at positive parities}

We have seen that there is no simple relationship in our data between the woman's age and her twinning rate. While we are working with these data, let us also check whether there really is a basis for the common impression that the twinning probability increases with a woman's parity. This turns out to be the case. To make sure we are not dealing with a compositional effect, we take into account the other covariates at our disposal.

To begin with, let us list the number of twin pairs born at the various birth orders during our period of observation (1961-1999), as seen in Table 6. We observe that most twins are delivered at the first birth and that the number of births declines strongly as we progress to higher-order births. This is partly a function of numbers under "risk", however, and our interest is centered on twin-birth intensities, not numbers of births. To study twinning rates, we introduce another simple multiplicative model, this time of the format $\mu_{i k n t}^{(2)}=\theta a_{i n} c_{k n} d_{n t}$, where $n$ stands for the mother's current parity (a time-varying covariate). The other covariates are (i) the woman's age group at the second birth, indexed by $i$, and (ii) calendar period, indexed by $k$, and the "time" variable $t$ stands for "months since previous birth". We list maximum-likelihood estimates of the parameters $\left\{a_{i n}\right\},\left\{c_{k n}\right\}$, and $\left\{d_{n t}\right\}$ (and some derivatives) in Table 7.

For our purpose, it suffices to use a coarser grouping than before of the woman's age groups and of the calendar periods. In order to be able to use the same intensity model for all parities and to avoid trivial problems with the time variable for parity 0 ("months since last previous birth" is not defined if there is no previous birth), we drop twinning at first births in the present analysis. ${ }^{15} \mathrm{We}$ stop the analysis at the first twin birth and lose very little information in this manner since a twin birth is a once-in-a-lifetime event for most couples. ${ }^{16}$ For the same reason, we also stop the analysis at the arrival of the tenth birth.

The estimates listed in Table 7 were used to produce Figures 15 to 17. In each diagram we see a strong drop in the twinning rate from the second to the third birth and a clear rise over subsequent birth orders. Figure 15 shows that this rise has declined over calendar time. Figure 16 reveals that the rise attenuates as the mother becomes older. Figure 17 shows a similar rise in the twinning rate over parities above

\footnotetext{
${ }^{14}$ There are very few births at the younger ages, therefore the left tail of the curve can be disregarded. The effect of age shown in Figure 13 is significant, but then most effects turn out to be significant at all normal levels of significance in a data set as large as ours.

${ }^{15}$ We studied twinning at first birth in Section 3 and now only lose a comparison of its risk with the twinning risk at parities 1 and above. We have found no sensible way of comparing the twinning probability in first and second birth and hedging against confounding with our covariates at the same time.

${ }^{16}$ This means that the records of women who had twins in their first delivery are not included in the present analysis. We studied twinning in second births, conditional on the multiplicity of the first birth, in Section 4 above.
} 
2 at each age of the previous child, and that this rise diminishes quickly as the child becomes older. It is striking how strongly the twinning rate increases with parity at very short birth intervals. At a birth interval of less than eighteen months, the twinning rate increases by a factor of 4 between the third and the sixth birth order. At intervals between eighteen and twenty-nine months, the corresponding rise is still almost threefold. At higher durations, the rise in the twinning rate is more modest. Twinning rates seem to be subject to strong selectivity in childbearing behavior, and we seem to have encountered yet another version of the empirical rule that early childbearing and quick follow-up entail high subsequent fertility. At each stage, the most fertile women have the highest chance of getting twins.

We believe that the strong drop in the twinning rate between birth order 2 and 3 may have the same explanation, applied in reverse. The twinning rate is the probability of having twins in a given confinement, given that there is such a confinement. Given the strength of the two-child norm in Sweden, we find it hard to believe that there is much selectivity in who has a second birth. We are not surprised, therefore, if any selectivity mechanism that produces twin births would be different for second births from what it is for later births. We are not sure that our finding of the fact that the twinning rate is higher at birth order 2 than at order 3 rather than the reverse really needs any deeper explanation.

\section{$\underline{\text { 8. Operational conclusions }}$}

Careful demographers regularly censor life histories at the arrival of a twin birth on the hunch that the demographic behavior of parents of twins must be different from the behavior of corresponding parents of singletons. The present paper shows that this is sensible practice, at least for Swedish women between the 1960s and 1990s. Since only about one per cent of births resulted in twins, the loss of information must be negligible in investigations of childbearing behavior, except possibly in data sets specially geared to studies of the parents of twins.

\section{Acknowledgement}

We are grateful for Susann Backer's most competent editorial help.

\section{$\underline{\text { References }}$}

Eriksson, Aldur W., and Johan Fellman, (1967a), Twinning and legitimacy. Hereditas 57:395-402

Eriksson, Aldur W., and Johan Fellman, (1967b), Twinning in relation to marital status of the mother. Acta Genetica et Statistica Medica 17: 385-398.

Eriksson, Aldur W., and Johan Feldman (1973), Differences in the twinning trends between Finns and Swedes. The American Journal of Human Genetics 25(2): 141-151.

Hoem, Britta and Jan M. Hoem (1996). Sweden's family policies and roller-coaster fertility. Journal of Population Problems (Tokyo), 52 (3-4), 1-22.

Hoem, Jan M. (1987). Statistical analysis of a multiplicative model and its application to the standardization of vital rates: A review. International Statistical Review 55, 119-152.

Högberg, Ulf, and Stig Wall (1992), Secular trends of twinning rates in Sweden. Journal of Biosocial Science 24:4. 
Lundin, Susanne (1996), Makten över kroppen. Lundin, Susanne, Lynn Åkesson (red.), Kroppens tid, identitet och samhälle. Natur och Kultur.

Pollard, G.N. (1969), Multiple births in Australia, 1944-63. Journal of Biosocial Science 1: 389-404.

Socialstyrelsen (1998), Förlossningar och barn födda efter provrörsbefruktningar 1982 - 1995. Stockholm: The (Swedish) National Board of Health and Welfare; SoS-rapport 1998:7.

Statistiska centralbyrån (SCB), Folkmängdens förändringar 1965. Stockholm: Statistics Sweden.

Statistiska centralbyrån (SCB), Annual publications of population statistics. Stockholm: Statistics Sweden.

Walke, Rainer (2001). Twins or two single children: The influence of the multiplicity of the first birth on the divorce risk of Swedish women. Max Planck Institute for Demographic Research Working Paper WP-2001-029. Download at http://www.demogr.mpg.de/Papers/Working/wp-2001-029.pdf 
Table 1. Singleton or twin first birth; relative risks for childless Swedish women

Singleton 1

Twin birth $\quad 0.009$

\begin{tabular}{lcccccc}
\hline Period & Singleton & $\begin{array}{c}\text { Twin } \\
\text { birth }\end{array}$ & Singleton & $\begin{array}{l}\text { Twin } \\
\text { birth }\end{array}$ & Singleton & $\begin{array}{c}\text { Twin } \\
\text { birth }\end{array}$ \\
\hline $1961-63$ & 1.461 & 0.010 & 1.461 & 0.919 & 1 & 0.007 \\
$1964-66$ & 1.613 & 0.011 & 1.613 & 1.049 & 1 & 0.007 \\
$1967-69$ & 1.440 & 0.009 & 1.440 & 0.868 & 1 & 0.006 \\
$1970-72$ & 1.364 & 0.009 & 1.364 & 0.886 & 1 & 0.007 \\
$1973-75$ & 1.323 & 0.009 & 1.323 & 0.877 & 1 & 0.007 \\
$1976-78$ & 1.080 & 0.008 & 1.080 & 0.727 & 1 & 0.007 \\
$1979-81$ & 0.972 & 0.008 & 0.972 & 0.760 & 1 & 0.008 \\
$1982-84$ & 0.868 & 0.008 & 0.868 & 0.730 & 1 & 0.009 \\
$1985-87$ & 0.891 & 0.008 & 0.891 & 0.804 & 1 & 0.009 \\
$1988-90$ & 1 & 0.010 & 1 & 1 & 1 & 0.010 \\
$1991-93$ & 0.950 & 0.013 & 0.950 & 1.249 & 1 & 0.014 \\
$1994-96$ & 0.778 & 0.013 & 0.778 & 1.234 & 1 & 0.016 \\
$1997-99$ & 0.674 & 0.013 & 0.674 & 1.239 & 1 & 0.019
\end{tabular}

\begin{tabular}{ccccccc}
\hline Age & Singleton & $\begin{array}{c}\text { Twin } \\
\text { birth }\end{array}$ & Singleton & $\begin{array}{c}\text { Twin } \\
\text { birth }\end{array}$ & Singleton & $\begin{array}{c}\text { Twin } \\
\text { birth }\end{array}$ \\
\hline $15-18$ & 0.071 & 0.000 & 0.071 & 0.030 & 1 & 0.005 \\
$19-21$ & 0.376 & 0.002 & 0.376 & 0.177 & 1 & 0.005 \\
$22-24$ & 0.664 & 0.005 & 0.664 & 0.404 & 1 & 0.007 \\
$25-27$ & 0.964 & 0.009 & 0.964 & 0.746 & 1 & 0.009 \\
$28-30$ & 1 & 0.012 & 1 & 1 & 1 & 0.012 \\
$31-33$ & 0.752 & 0.012 & 0.752 & 1.062 & 1 & 0.016 \\
$34-36$ & 0.445 & 0.009 & 0.445 & 0.811 & 1 & 0.021 \\
$37-39$ & 0.223 & 0.005 & 0.223 & 0.459 & 1 & 0.024 \\
$40-42$ & 0.085 & 0.002 & 0.085 & 0.137 & 1 & 0.019 \\
$43-45$ & 0.019 & 0.000 & 0.019 & 0.022 & 1 & 0.013 \\
$46-$ & 0.001 & 0.000 & 0.001 & 0.003 & 1 & 0.030 \\
\hline
\end{tabular}

Table 2. Singleton or twin second birth; relative risks for Swedish women according to the multiplicity of their first birth

\begin{tabular}{lcc}
\hline & \multicolumn{2}{c}{ Second birth } \\
\cline { 2 - 3 } First birth & Singleton & Twin birth \\
\hline Singleton & 1 & 0.010 \\
Twin birth & 0.338 & 0.007 \\
\hline
\end{tabular}

Note. Standardized for mother's age at first birth, current calendar period, and time since first birth, given in Table 3 . 
Table 3. Second birth; relative risks for Swedish women according to the multiplicity of their first birth

First birth:

Singleton

1

Twin birth

0.342

\begin{tabular}{|c|c|c|c|c|c|c|}
\hline \multirow[b]{2}{*}{ Period } & \multicolumn{2}{|c|}{ First birth } & \multicolumn{2}{|c|}{ First birth } & \multicolumn{2}{|c|}{ First birth } \\
\hline & Singleton & Twin birth & Singleton & Twin birth & Singleton & Twin birth \\
\hline $1961-63$ & 0.648 & 0.279 & 1 & 0.430 & 0.648 & 0.828 \\
\hline $1964-66$ & 0.744 & 0.344 & 1 & 0.462 & 0.744 & 1.021 \\
\hline $1967-69$ & 0.652 & 0.252 & 1 & 0.386 & 0.652 & 0.748 \\
\hline $1970-72$ & 0.634 & 0.248 & 1 & 0.391 & 0.634 & 0.736 \\
\hline 1973-75 & 0.640 & 0.248 & 1 & 0.387 & 0.640 & 0.736 \\
\hline $1976-78$ & 0.607 & 0.206 & 1 & 0.340 & 0.607 & 0.612 \\
\hline $1979-81$ & 0.665 & 0.223 & 1 & 0.336 & 0.665 & 0.663 \\
\hline $1982-84$ & 0.712 & 0.250 & 1 & 0.351 & 0.712 & 0.741 \\
\hline $1985-87$ & 0.839 & 0.306 & 1 & 0.365 & 0.839 & 0.910 \\
\hline $1988-90$ & 0.997 & 0.330 & 1 & 0.331 & 0.997 & 0.980 \\
\hline $1991-93$ & 1 & 0.337 & 1 & 0.337 & 1 & 1 \\
\hline $1994-96$ & 0.873 & 0.245 & 1 & 0.280 & 0.873 & 0.726 \\
\hline $1997-99$ & 0.801 & 0.195 & 1 & 0.243 & 0.801 & 0.578 \\
\hline
\end{tabular}

\begin{tabular}{|c|c|c|c|c|c|c|}
\hline \multirow{2}{*}{$\begin{array}{l}\text { Age at first } \\
\text { birth }\end{array}$} & \multicolumn{2}{|c|}{ First birth } & \multicolumn{2}{|c|}{ First birth } & \multicolumn{2}{|c|}{ First birth } \\
\hline & Singleton & Twin birth & Singleton & Twin birth & Singleton & Twin birth \\
\hline $15-18$ & 0.857 & 0.523 & 1 & 0.611 & 0.857 & 1.390 \\
\hline $19-21$ & 0.938 & 0.482 & 1 & 0.514 & 0.938 & 1.279 \\
\hline $22-24$ & 1 & 0.377 & 1 & 0.377 & 1 & 1 \\
\hline $25-27$ & 0.978 & 0.303 & 1 & 0.310 & 0.978 & 0.805 \\
\hline $28-30$ & 0.835 & 0.225 & 1 & 0.270 & 0.835 & 0.597 \\
\hline $31-33$ & 0.625 & 0.170 & 1 & 0.272 & 0.625 & 0.452 \\
\hline $34-36$ & 0.402 & 0.085 & 1 & 0.211 & 0.402 & 0.225 \\
\hline $37-39$ & 0.223 & 0.050 & 1 & 0.225 & 0.223 & 0.133 \\
\hline $40-42$ & 0.096 & 0.041 & 1 & 0.423 & 0.096 & 0.108 \\
\hline $43-45$ & 0.029 & & 1 & & 0.029 & \\
\hline 46- & 0.006 & & 1 & & 0.006 & \\
\hline
\end{tabular}

\begin{tabular}{|c|c|c|c|c|c|c|}
\hline \multirow{2}{*}{$\begin{array}{l}\text { Age of first } \\
\text { child } \\
\text { (months) }\end{array}$} & \multicolumn{2}{|c|}{ First birth } & \multicolumn{2}{|c|}{ First birth } & \multicolumn{2}{|c|}{ First birth } \\
\hline & Singleton & Twin birth & Singleton & Twin birth & Singleton & Twin birth \\
\hline $0-11$ & 0.006 & 0.005 & 1 & 0.787 & 0.006 & 0.021 \\
\hline $12-17$ & 0.249 & 0.127 & 1 & 0.510 & 0.249 & 0.529 \\
\hline $18-23$ & 0.652 & 0.187 & 1 & 0.286 & 0.652 & 0.778 \\
\hline $24-29$ & 0.929 & 0.227 & 1 & 0.244 & 0.929 & 0.945 \\
\hline $30-35$ & 1 & 0.240 & 1 & 0.240 & 1 & 1 \\
\hline $36-47$ & 0.965 & 0.247 & 1 & 0.256 & 0.965 & 1.030 \\
\hline $48-59$ & 0.725 & 0.267 & 1 & 0.368 & 0.725 & 1.112 \\
\hline $60-83$ & 0.438 & 0.207 & 1 & 0.472 & 0.438 & 0.863 \\
\hline 84-107 & 0.234 & 0.128 & 1 & 0.547 & 0.234 & 0.533 \\
\hline $108-120$ & 0.131 & 0.071 & 1 & 0.543 & 0.131 & 0.297 \\
\hline
\end{tabular}


Table 4. Birth of third child; relative risks for Swedish women according to whether their first two children were twins or singletons

First two children:

Two singletons

1

One twin birth

1.010

\begin{tabular}{|c|c|c|c|c|c|c|}
\hline \multirow[b]{2}{*}{ Period } & \multicolumn{2}{|c|}{ First two children } & \multicolumn{2}{|c|}{ First two children } & \multicolumn{2}{|c|}{ First two children } \\
\hline & $\begin{array}{c}\text { Two } \\
\text { singletons }\end{array}$ & $\begin{array}{l}\text { One twin } \\
\text { birth }\end{array}$ & $\begin{array}{c}\text { Two } \\
\text { singletons }\end{array}$ & $\begin{array}{l}\text { One twin } \\
\text { birth }\end{array}$ & $\begin{array}{c}\text { Two } \\
\text { singletons }\end{array}$ & $\begin{array}{l}\text { One twin } \\
\text { birth }\end{array}$ \\
\hline 1961-63 & 0.880 & 0.724 & 1 & 0.822 & 0.880 & 0.746 \\
\hline $1964-66$ & 0.939 & 0.885 & 1 & 0.942 & 0.939 & 0.912 \\
\hline $1967-69$ & 0.687 & 0.630 & 1 & 0.917 & 0.687 & 0.650 \\
\hline 1970-72 & 0.583 & 0.610 & 1 & 1.046 & 0.583 & 0.629 \\
\hline 1973-75 & 0.551 & 0.623 & 1 & 1.131 & 0.551 & 0.642 \\
\hline $1976-78$ & 0.468 & 0.531 & 1 & 1.134 & 0.468 & 0.548 \\
\hline $1979-81$ & 0.585 & 0.581 & 1 & 0.993 & 0.585 & 0.599 \\
\hline $1982-84$ & 0.664 & 0.675 & 1 & 1.016 & 0.664 & 0.695 \\
\hline $1985-87$ & 0.843 & 0.862 & 1 & 1.022 & 0.843 & 0.889 \\
\hline $1988-90$ & 1 & 0.970 & 1 & 0.970 & 1 & 1 \\
\hline 1991-93 & 0.995 & 1.021 & 1 & 1.026 & 0.995 & 1.053 \\
\hline 1994-96 & 0.719 & 0.771 & 1 & 1.073 & 0.719 & 0.795 \\
\hline 1997-99 & 0.588 & 0.631 & 1 & 1.073 & 0.588 & 0.650 \\
\hline
\end{tabular}

\begin{tabular}{|c|c|c|c|c|c|c|}
\hline \multirow{2}{*}{$\begin{array}{l}\text { Age at first } \\
\text { birth }\end{array}$} & \multicolumn{2}{|c|}{ First two children } & \multicolumn{2}{|c|}{ First two children } & \multicolumn{2}{|c|}{ First two children } \\
\hline & $\begin{array}{c}\text { Two } \\
\text { singletons }\end{array}$ & $\begin{array}{l}\text { One twin } \\
\text { birth }\end{array}$ & $\begin{array}{c}\text { Two } \\
\text { singletons }\end{array}$ & $\begin{array}{l}\text { One twin } \\
\text { birth }\end{array}$ & $\begin{array}{c}\text { Two } \\
\text { singletons }\end{array}$ & $\begin{array}{l}\text { One twin } \\
\text { birth }\end{array}$ \\
\hline $15-18$ & 1 & 0.753 & 1 & 0.753 & 1 & 1 \\
\hline $19-21$ & 0.771 & 0.688 & 1 & 0.893 & 0.771 & 0.914 \\
\hline $22-24$ & 0.561 & 0.551 & 1 & 0.982 & 0.561 & 0.732 \\
\hline $25-27$ & 0.411 & 0.449 & 1 & 1.091 & 0.411 & 0.596 \\
\hline $28-30$ & 0.301 & 0.338 & 1 & 1.121 & 0.301 & 0.449 \\
\hline $31-33$ & 0.215 & 0.262 & 1 & 1.217 & 0.215 & 0.347 \\
\hline $34-36$ & 0.146 & 0.134 & 1 & 0.918 & 0.146 & 0.178 \\
\hline $37-39$ & 0.093 & 0.082 & 1 & 0.875 & 0.093 & 0.108 \\
\hline $40-42$ & 0.045 & 0.065 & 1 & 1.464 & 0.045 & 0.087 \\
\hline $43-45$ & 0.013 & 0 & 1 & 0 & 0.013 & 0 \\
\hline $46+$ & 0.008 & 0 & 1 & 0 & 0.008 & 0 \\
\hline
\end{tabular}

\begin{tabular}{|c|c|c|c|c|c|c|}
\hline \multirow{2}{*}{$\begin{array}{c}\text { Age of } \\
\text { previous } \\
\text { child (years) }\end{array}$} & \multicolumn{2}{|c|}{ First two children } & \multicolumn{2}{|c|}{ First two children } & \multicolumn{2}{|c|}{ First two children } \\
\hline & $\begin{array}{c}\text { Two } \\
\text { singletons }\end{array}$ & $\begin{array}{l}\text { One twin } \\
\text { birth }\end{array}$ & $\begin{array}{c}\text { Two } \\
\text { singletons }\end{array}$ & $\begin{array}{l}\text { One twin } \\
\text { birth }\end{array}$ & $\begin{array}{c}\text { Two } \\
\text { singletons }\end{array}$ & $\begin{array}{l}\text { One twin } \\
\text { birth }\end{array}$ \\
\hline 0 & 0.015 & 0.018 & 1 & 1.212 & 0.015 & 0.022 \\
\hline 1 & 0.508 & 0.468 & 1 & 0.922 & 0.508 & 0.556 \\
\hline 1.5 & 0.907 & 0.690 & 1 & 0.761 & 0.907 & 0.820 \\
\hline 2 & 1 & 0.842 & 1 & 0.842 & 1 & 1 \\
\hline 2.5 & 0.969 & 0.894 & 1 & 0.923 & 0.969 & 1.062 \\
\hline 3 & 0.966 & 0.928 & 1 & 0.960 & 0.966 & 1.102 \\
\hline 4 & 0.909 & 1.005 & 1 & 1.106 & 0.909 & 1.193 \\
\hline $5-6$ & 0.676 & 0.781 & 1 & 1.156 & 0.676 & 0.928 \\
\hline $7-8$ & 0.399 & 0.481 & 1 & 1.207 & 0.399 & 0.571 \\
\hline $9-10$ & 0.223 & 0.267 & 1 & 1.198 & 0.223 & 0.317 \\
\hline
\end{tabular}


Table 5. Third births; relative risks for mothers of one set of twins and one singleton

Previous births:

Singleton and then twins

Twins and then singleton

1,982

\begin{tabular}{|c|c|c|c|c|c|c|}
\hline & \multicolumn{2}{|c|}{ Previous births } & \multicolumn{2}{|c|}{ Previous births } & \multicolumn{2}{|c|}{ Previous births } \\
\hline Period & $\begin{array}{c}\text { Singleton } \\
\text { and then } \\
\text { twins }\end{array}$ & $\begin{array}{l}\text { Twins and } \\
\text { then } \\
\text { singleton }\end{array}$ & $\begin{array}{l}\text { Singleton } \\
\text { and then } \\
\text { twins }\end{array}$ & $\begin{array}{l}\text { Twins and } \\
\text { then } \\
\text { singleton }\end{array}$ & $\begin{array}{l}\text { Singleton } \\
\text { and then } \\
\text { twins }\end{array}$ & $\begin{array}{c}\text { Twins and } \\
\text { then } \\
\text { singleton }\end{array}$ \\
\hline $1961-63$ & 1,218 & 1,721 & 1 & 1,414 & 1,330 & 0,792 \\
\hline $1964-66$ & 1,113 & 1,908 & 1 & 1,714 & 1,215 & 0,879 \\
\hline $1967-69$ & 0,782 & 1,375 & 1 & 1,758 & 0,854 & 0,633 \\
\hline $1970-72$ & 0,534 & 1,338 & 1 & 2,507 & 0,583 & 0,616 \\
\hline $1973-75$ & 0,531 & 1,166 & 1 & 2,196 & 0,580 & 0,537 \\
\hline $1976-78$ & 0,427 & 0,895 & 1 & 2,096 & 0,467 & 0,412 \\
\hline $1979-81$ & 0,544 & 1,203 & 1 & 2,211 & 0,594 & 0,554 \\
\hline $1982-84$ & 0,579 & 1,275 & 1 & 2,202 & 0,632 & 0,587 \\
\hline $1985-87$ & 0,840 & 1,490 & 1 & 1,774 & 0,917 & 0,686 \\
\hline $1988-90$ & 1 & 2,060 & 1 & 2,060 & 1,092 & 0,948 \\
\hline $1991-93$ & 0,916 & 2,172 & 1 & 2,372 & 1 & 1 \\
\hline $1994-96$ & 0,697 & 1,291 & 1 & 1,852 & 0,762 & 0,595 \\
\hline 1997-99 & 0,531 & 1,085 & 1 & 2,043 & 0,580 & 0,500 \\
\hline
\end{tabular}

\begin{tabular}{|c|c|c|c|c|c|c|}
\hline \multirow[b]{2}{*}{$\begin{array}{l}\text { Age at second } \\
\text { confinement }\end{array}$} & \multicolumn{2}{|c|}{ Previous births } & \multicolumn{2}{|c|}{ Previous births } & \multicolumn{2}{|c|}{ Previous births } \\
\hline & $\begin{array}{l}\text { Singleton } \\
\text { and then } \\
\text { twins }\end{array}$ & $\begin{array}{l}\text { Twins and } \\
\text { then } \\
\text { singleton }\end{array}$ & $\begin{array}{l}\text { Singleton } \\
\text { and then } \\
\text { twins }\end{array}$ & $\begin{array}{l}\text { Twins and } \\
\text { then } \\
\text { singleton }\end{array}$ & $\begin{array}{l}\text { Singleton } \\
\text { and then } \\
\text { twins }\end{array}$ & $\begin{array}{c}\text { Twins and } \\
\text { then } \\
\text { singleton }\end{array}$ \\
\hline-18 & 1,337 & 3,109 & 1 & 2,325 & 1,337 & 2,729 \\
\hline $19-21$ & 1 & 1,139 & 1 & 1,139 & 1 & 1 \\
\hline $22-24$ & 0,541 & 1,032 & 1 & 1,906 & 0,541 & 0,906 \\
\hline $25-27$ & 0,351 & 0,747 & 1 & 2,128 & 0,351 & 0,656 \\
\hline $28-30$ & 0,218 & 0,497 & 1 & 2,279 & 0,218 & 0,436 \\
\hline $31-33$ & 0,174 & 0,331 & 1 & 1,903 & 0,174 & 0,290 \\
\hline $34-36$ & 0,124 & 0,262 & 1 & 2,118 & 0,124 & 0,230 \\
\hline $37-39$ & 0,056 & 0,194 & 1 & 3,459 & 0,056 & 0,170 \\
\hline $40-42$ & 0,016 & 0,168 & 1 & 10,548 & 0,016 & 0,147 \\
\hline $43-45$ & 0 & 0,284 & & & 0 & 0,249 \\
\hline
\end{tabular}

\begin{tabular}{|c|c|c|c|c|c|c|}
\hline \multirow[b]{2}{*}{$\begin{array}{l}\text { Years since } \\
\text { previous birth }\end{array}$} & \multicolumn{2}{|c|}{ Previous births } & \multicolumn{2}{|c|}{ Previous births } & \multicolumn{2}{|c|}{ Previous births } \\
\hline & $\begin{array}{c}\text { Singleton } \\
\text { and then } \\
\text { twins } \\
\end{array}$ & $\begin{array}{c}\text { Twins and } \\
\text { then } \\
\text { singleton }\end{array}$ & $\begin{array}{c}\text { Singleton } \\
\text { and then } \\
\text { twins }\end{array}$ & $\begin{array}{c}\text { Twins and } \\
\text { then } \\
\text { singleton }\end{array}$ & $\begin{array}{c}\text { Singleton } \\
\text { and then } \\
\text { twins }\end{array}$ & $\begin{array}{c}\text { Twins and } \\
\text { then } \\
\text { singleton } \\
\end{array}$ \\
\hline 0 & 0,021 & 0,050 & 1 & 2,391 & 0,021 & 0,023 \\
\hline 1 & 0,603 & 1,298 & 1 & 2,154 & 0,603 & 0,604 \\
\hline 1,5 & 0,782 & 2,318 & 1 & 2,964 & 0,782 & 1,078 \\
\hline 2 & 1 & 2,150 & 1 & 2,150 & 1 & 1 \\
\hline 2,5 & 0,688 & 1,591 & 1 & 2,312 & 0,688 & 0,74 \\
\hline 3 & 0,717 & 1,911 & 1 & 2,664 & 0,717 & 0,889 \\
\hline 4 & 0,828 & 1,511 & 1 & 1,826 & 0,828 & 0,703 \\
\hline $5-6$ & 0,740 & 1,186 & 1 & 1,603 & 0,740 & 0,552 \\
\hline $7-8$ & 0,539 & 0,719 & 1 & 1,335 & 0,539 & 0,335 \\
\hline $9-10$ & 0,307 & 0,522 & 1 & 1,699 & 0,307 & 0,243 \\
\hline
\end{tabular}


Table 6. Number of twin births in our data set, by birth order

\begin{tabular}{cr}
\hline Birth order & $\begin{array}{r}\text { Number of } \\
\text { twin births }\end{array}$ \\
\hline 1 & 14376 \\
2 & 12772 \\
3 & 5593 \\
4 & 1666 \\
5 & 556 \\
6 & 211 \\
7 & 79 \\
8 & 36 \\
9 & 13 \\
10 & 8 \\
11 & 1 \\
12 & 3 \\
\hline Total & 35314 \\
\hline
\end{tabular}


Table 7. Twin births by birth order; relative risks

\begin{tabular}{|c|c|c|c|c|c|c|c|}
\hline $\begin{array}{l}\text { Birth } \\
\text { order }\end{array}$ & 1961-99 & $1961-78$ & 1979-93 & 1994-99 & $1961-78$ & $1979-93$ & 1994-99 \\
\hline 2 & 1 & 1 & 1.458 & 2.004 & 1 & 1 & 1 \\
\hline 3 & 0.319 & 0.394 & 0.450 & 0.422 & 0.394 & 0.308 & 0.21 \\
\hline 4 & 0.247 & 0.354 & 0.309 & 0.290 & 0.354 & 0.212 & 0.145 \\
\hline 5 & 0.335 & 0.457 & 0.428 & 0.397 & 0.457 & 0.293 & 0.198 \\
\hline 6 & 0.524 & 0.611 & 0.834 & 0.556 & 0.611 & 0.572 & 0.277 \\
\hline 7 & 0.682 & 0.848 & 0.644 & 1.270 & 0.848 & 0.441 & 0.634 \\
\hline 8 & 0.958 & 1.110 & 1.262 & 1.422 & 1.11 & 0.865 & 0.71 \\
\hline 9 & 1.035 & 1.502 & 1.250 & & 1.502 & 0.857 & 0 \\
\hline 10 & 1.729 & 2.081 & 3.188 & & 2.081 & 2.186 & 0 \\
\hline
\end{tabular}

\begin{tabular}{|c|c|c|c|c|c|c|c|c|}
\hline & \multicolumn{4}{|c|}{ Woman's age at last previous birth } & \multicolumn{4}{|c|}{ Woman's age at last previous birth } \\
\hline Birth order & -24 & $25-29$ & $30-34$ & $35-$ & -24 & $25-29$ & $30-34$ & $35-$ \\
\hline 2 & 1 & 1,262 & 1,181 & 0,593 & 1 & 1 & 1 & 1 \\
\hline 3 & 0,555 & 0,380 & 0,260 & 0,130 & 0,555 & 0,301 & 0,22 & 0,219 \\
\hline 4 & 0,637 & 0,372 & 0,184 & 0,090 & 0,637 & 0,295 & 0,156 & 0,151 \\
\hline 5 & 0,550 & 0,523 & 0,323 & 0,113 & 0,550 & 0,415 & 0,273 & 0,191 \\
\hline 6 & 0 & 0,745 & 0,515 & 0,221 & 0 & 0,590 & 0,436 & 0,372 \\
\hline 7 & 0 & 0,955 & 0,688 & 0,289 & 0 & 0,757 & 0,582 & 0,486 \\
\hline 8 & 0 & 0,522 & 1,197 & 0,380 & 0 & 0,413 & 1,013 & 0,640 \\
\hline 9 & 0 & 3,763 & 0,988 & 0,436 & 0 & 2,981 & 0,837 & 0,734 \\
\hline 10 & & 0 & 0,959 & 0,878 & & 0 & 0,812 & 1,481 \\
\hline
\end{tabular}

\begin{tabular}{|c|c|c|c|c|c|c|c|c|}
\hline & \multicolumn{4}{|c|}{ Years since last previous birth } & \multicolumn{4}{|c|}{ Years since last previous birth } \\
\hline$\overline{\text { Birth order }}$ & $-1,5$ & 2,5 & 5 & $>5$ & $-1,5$ & 2,5 & 5 & $>5$ \\
\hline 2 & 1 & 9,258 & 10,256 & 3,779 & 1 & 1 & $\overline{1}$ & 1 \\
\hline 3 & 0,523 & 2,805 & 2,873 & 1,372 & 0,523 & 0,303 & 0,28 & 0,363 \\
\hline 4 & 0,625 & 2,531 & 2,014 & 1,000 & 0,625 & 0,273 & 0,196 & 0,265 \\
\hline 5 & 1,003 & 3,774 & 2,663 & 1,266 & 1,003 & 0,408 & 0,260 & 0,335 \\
\hline 6 & 2,113 & 7,795 & 4,003 & 1,366 & 2,113 & 0,842 & 0,390 & 0,361 \\
\hline 7 & 2,741 & 9,512 & 5,646 & 1,634 & 2,741 & 1,027 & 0,551 & 0,432 \\
\hline 8 & 5,104 & 15,021 & 9,153 & 0,629 & 5,104 & 1,622 & 0,892 & 0,166 \\
\hline 9 & 4,024 & 17,975 & 5,527 & 2,894 & 4,024 & 1,942 & 0,539 & 0,766 \\
\hline 10 & 5,021 & 28,485 & 5,051 & 7,997 & 5,021 & 3,077 & 0,492 & 2,116 \\
\hline
\end{tabular}


Figure 1. Twin births as a fraction of total births, 1871-1998.

Per 1000

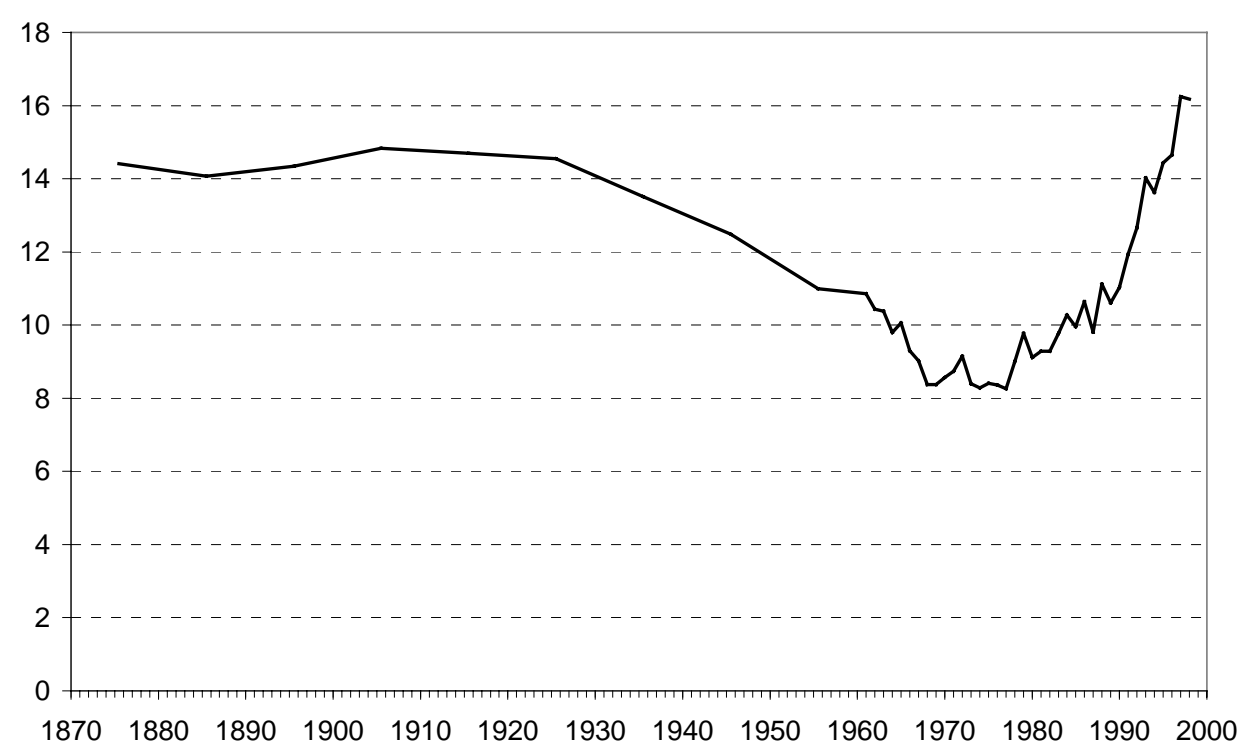

Note. The fraction of twin births is computed as the number of twin births (counting live and still births) divided by the total number of births in each year.

Sources:

For years 1871-1965: Folkmängdens förändringar 1965, tabell 7:3 (SCB 1965), For years 1955-1998: Annual publications of population statistics (SCB).

Figure 2. Mean age of mother at birth

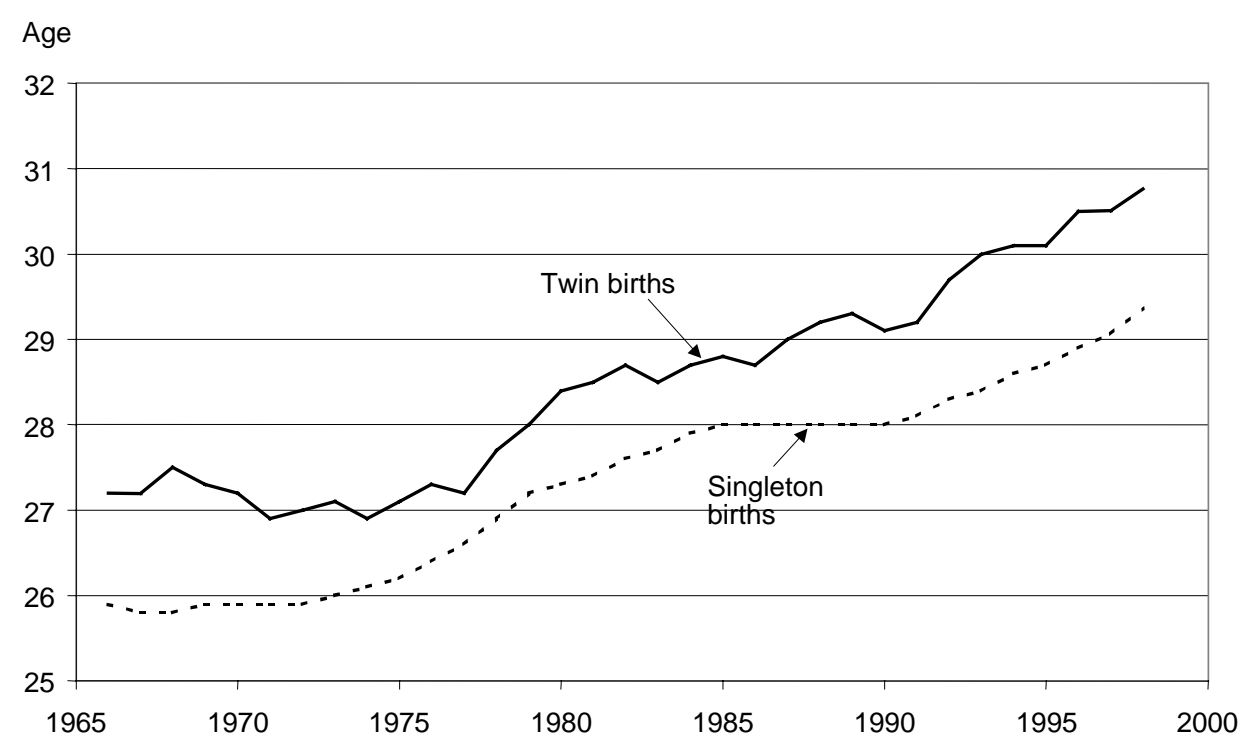

Sources:

Annual publications of population statistics (SCB). 
Figure 3. Fraction of twins, by age of mothers. Per 1000

A. Age 16-30

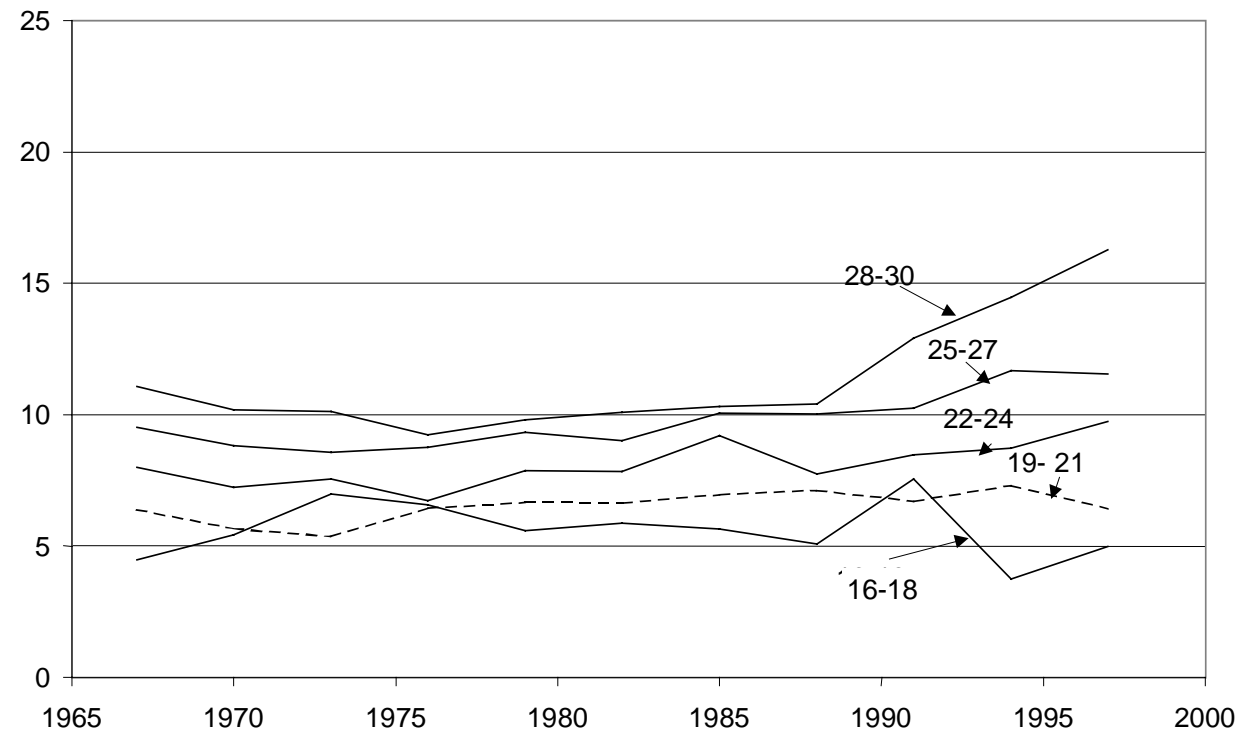

B. Age 31-45

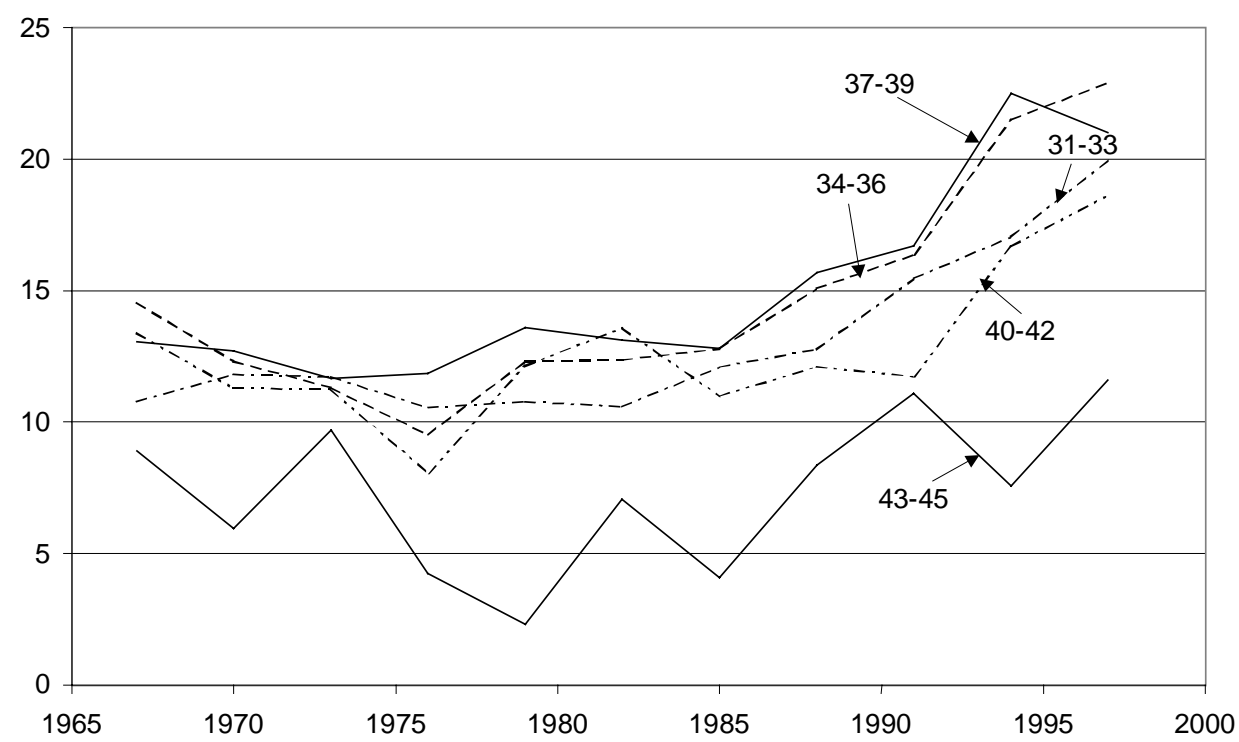

Sources:

Annual publications of population statistics (SCB). 
Figure 4. Annual index of the fraction of twins

$1977=1$

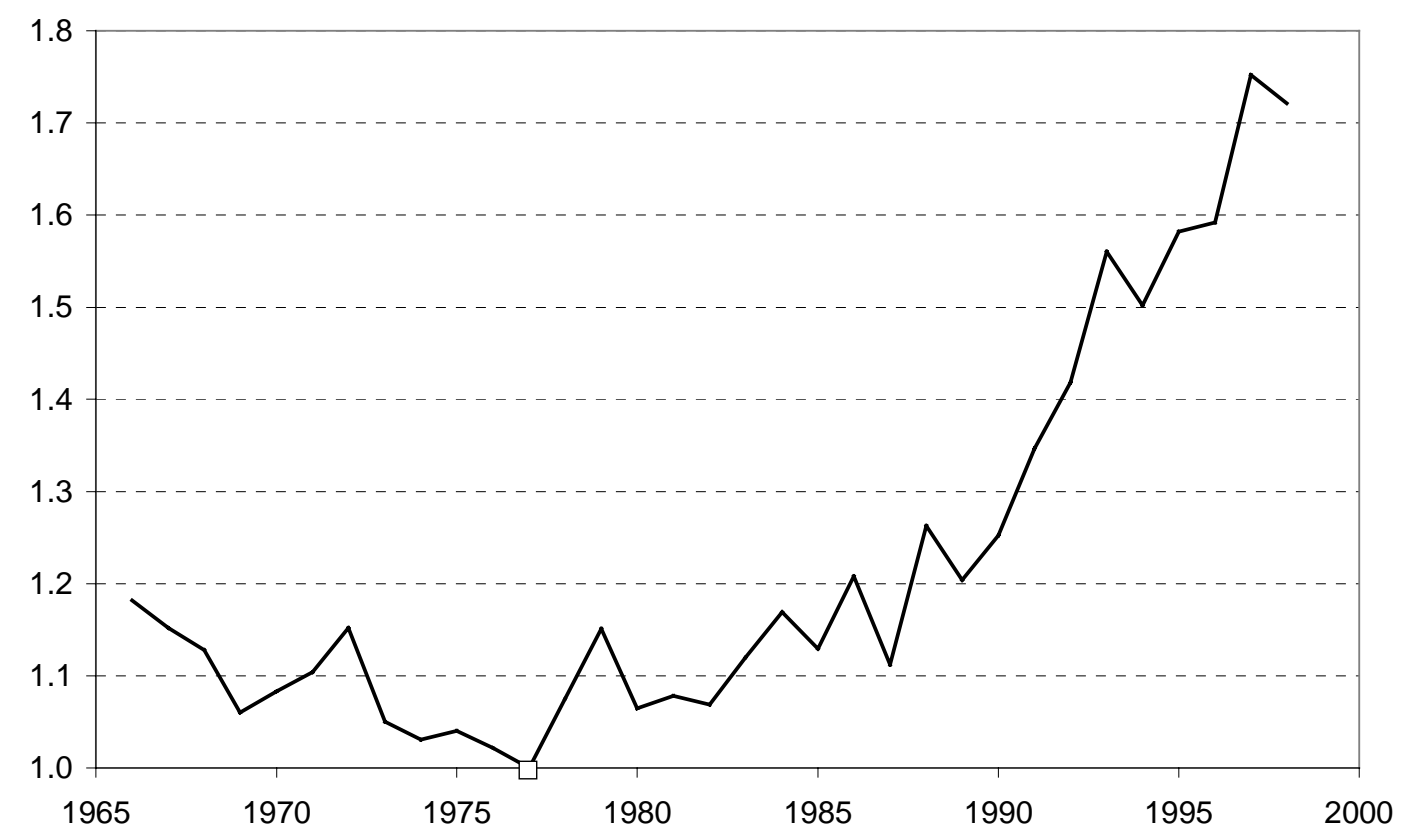

Note. Standardized for age.

Sources: Annual publications of population statistics (SCB).

Figure 5. Annual index of first-birth rates, separately for singleton and twin births

\section{$1990=1$}

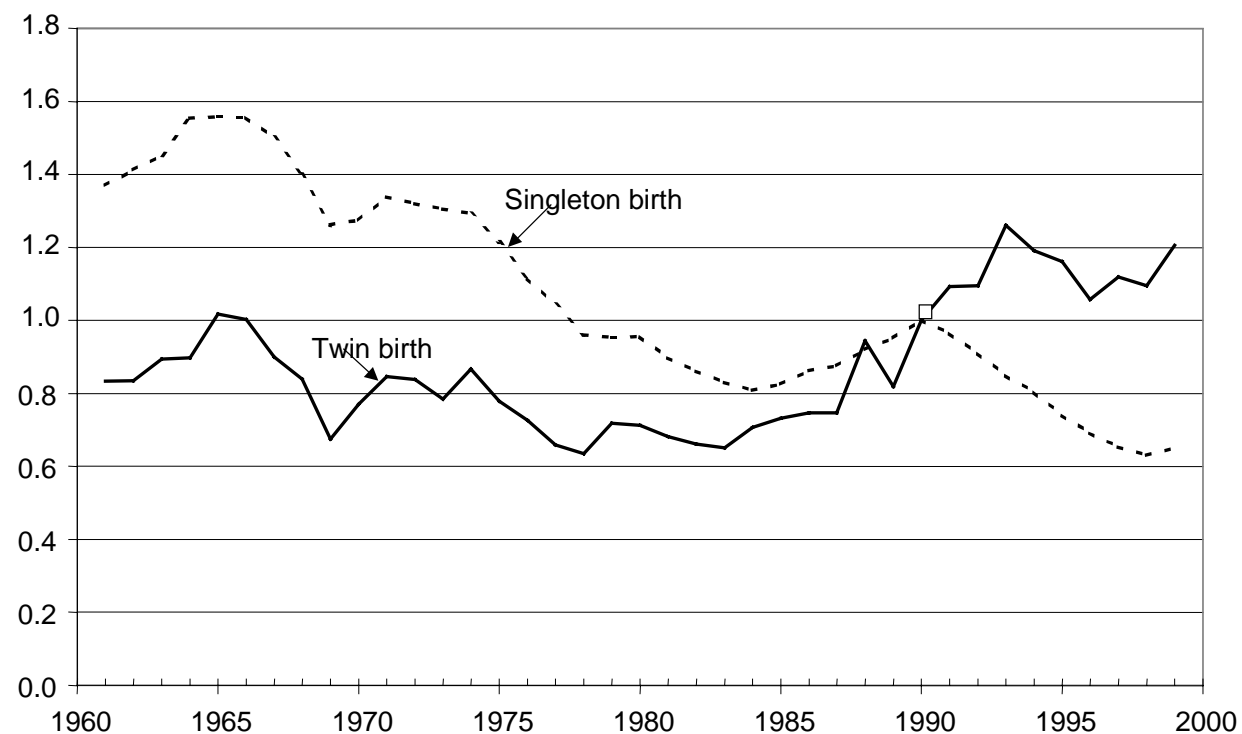

Note. Standardized for age.

Source: Table 1 
Figure 6. Age profile of intensities of singleton births and twin births

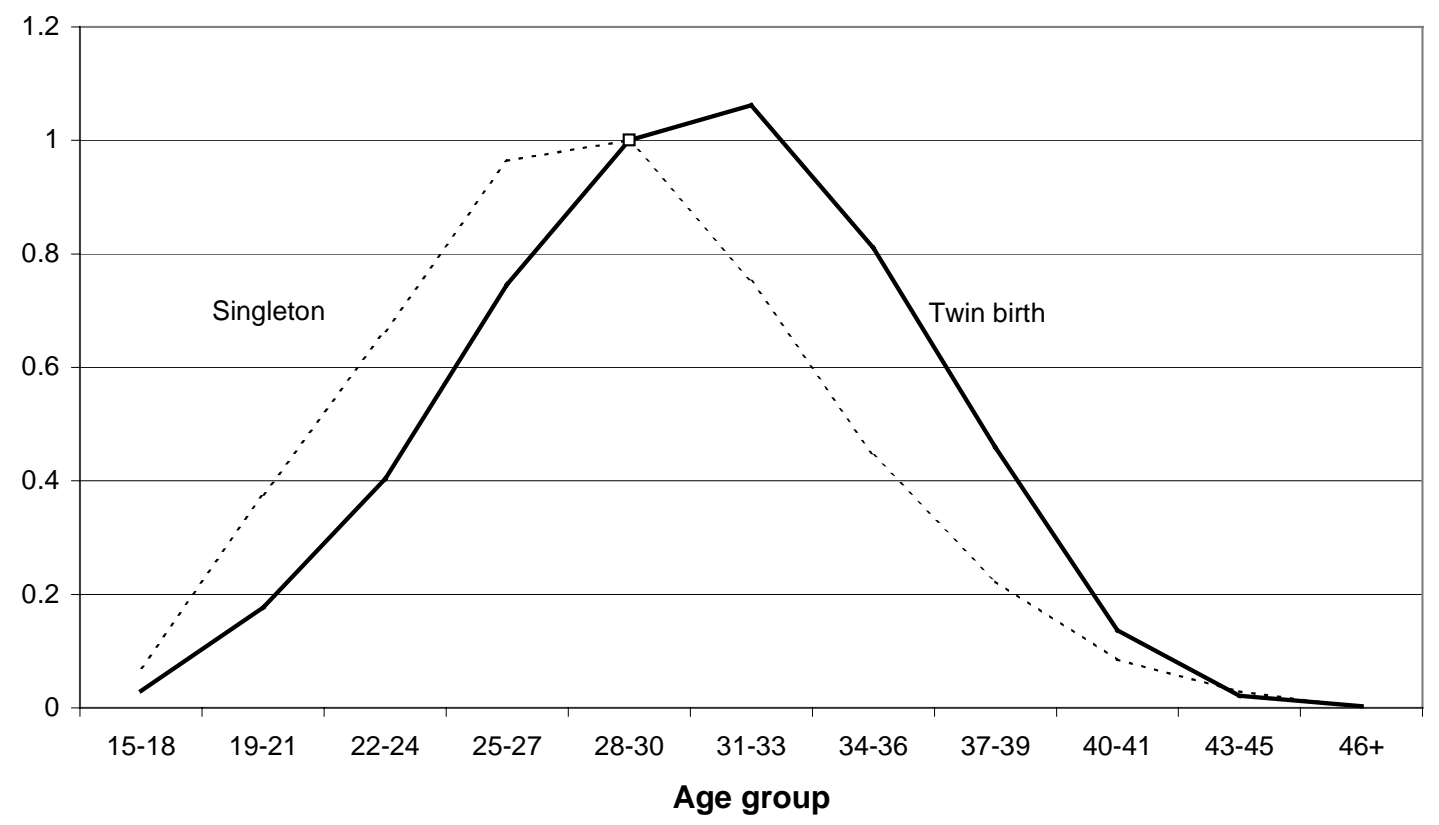

Source: Table 1

Figure 7. Second births; annual index for mothers with a singleton or a twin birth respectively

$1991-93=1$

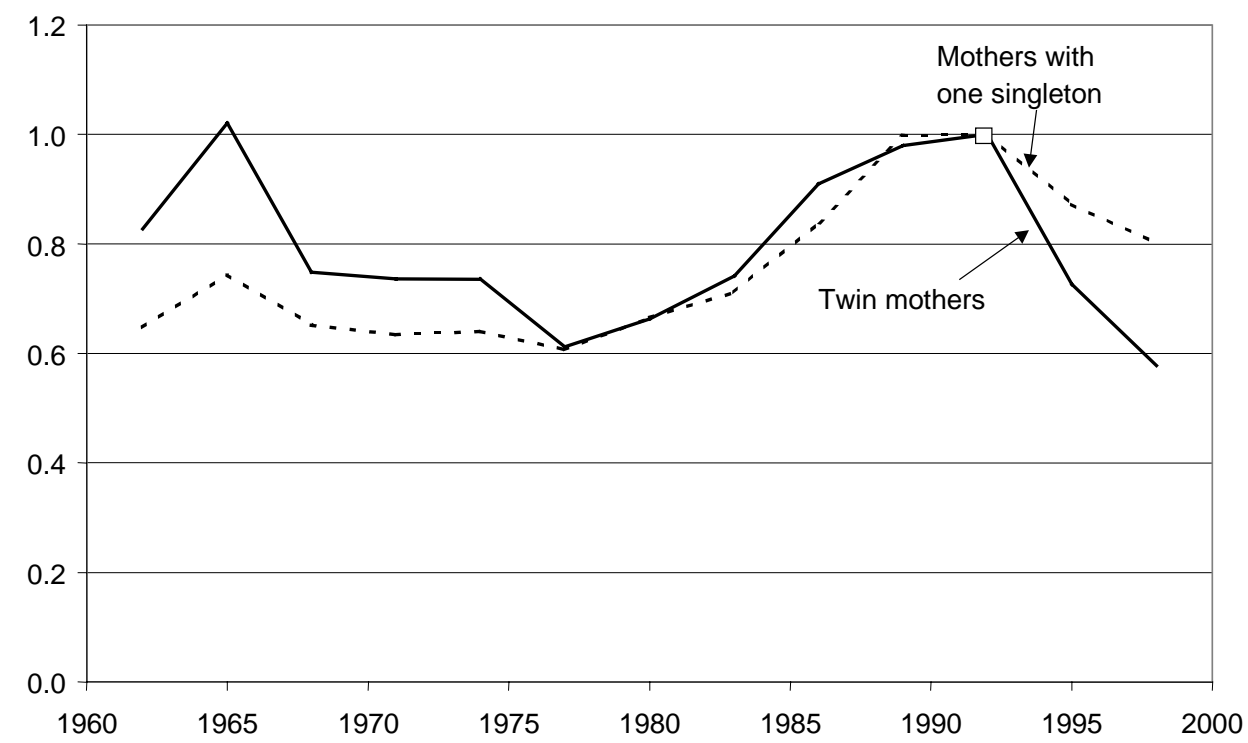

Note. Three-year calendar periods. Standardized for the mother's age at first birth and for time since that birth.

Source: Table 3. 
Figure 8. Second births, by woman's age; relative risks for women with a singleton or a twin birth respectively

20-24 years $=1$

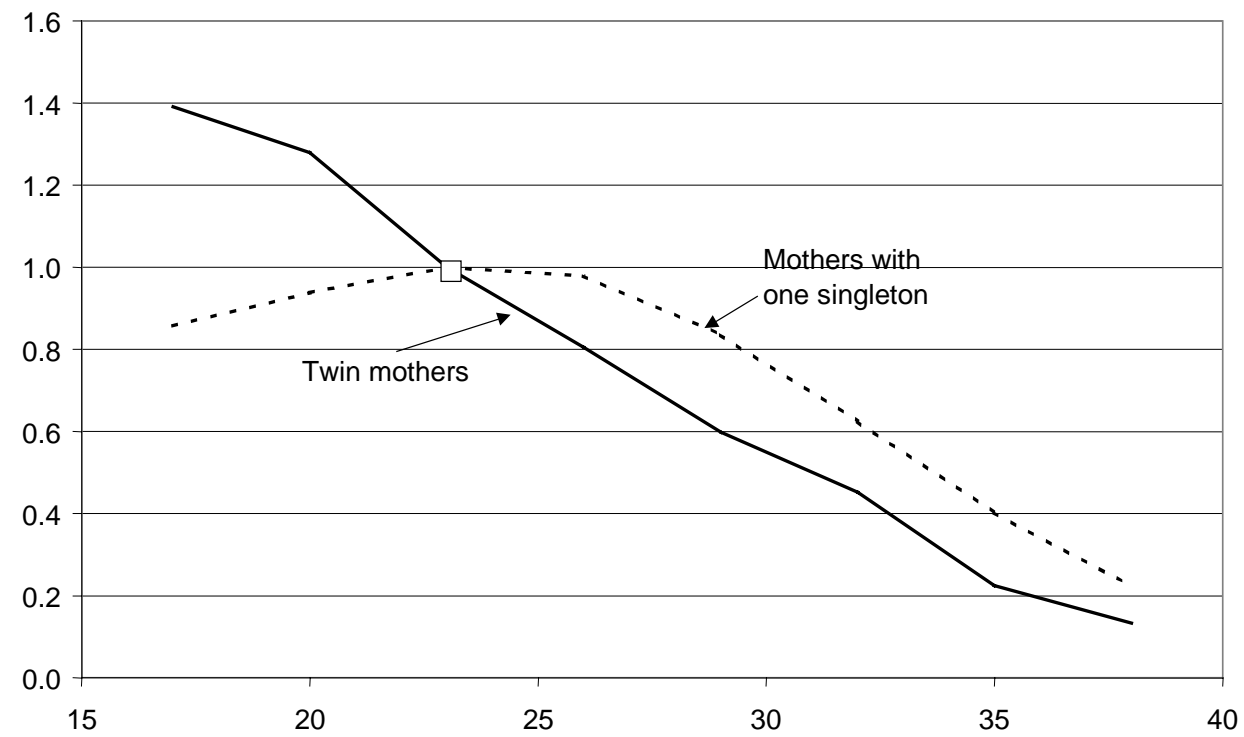

Note. Standardized for calendar period and for time since first birth.

Source: Table 3.

Figure 9. Second births, by years since first confinement;

2,5 years $=1$ relative risks for women with a singleton or a twin birth respectively

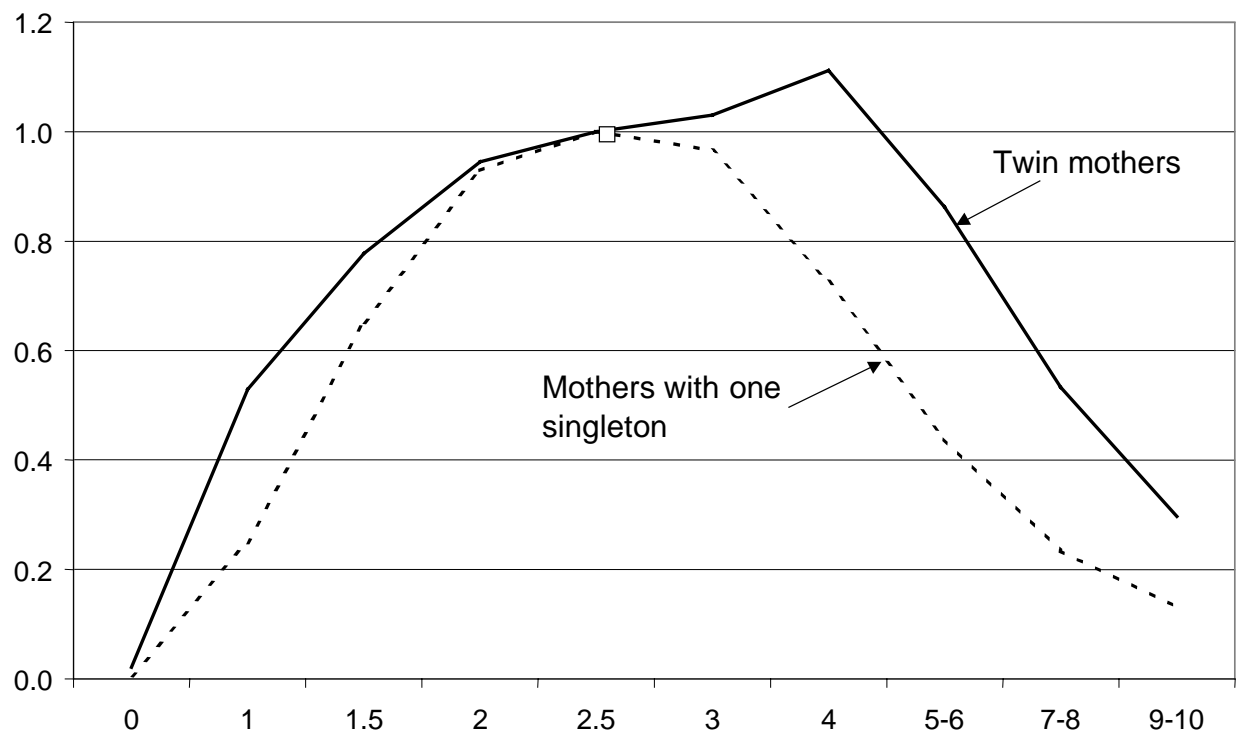

Note. Standardized for calendar period and for woman's age at first birth.

Age of

child

Source: Table 3. 
Figure 10. Next birth; annual index for women with two singletons or one twin birth respectively

$1988-90=1$

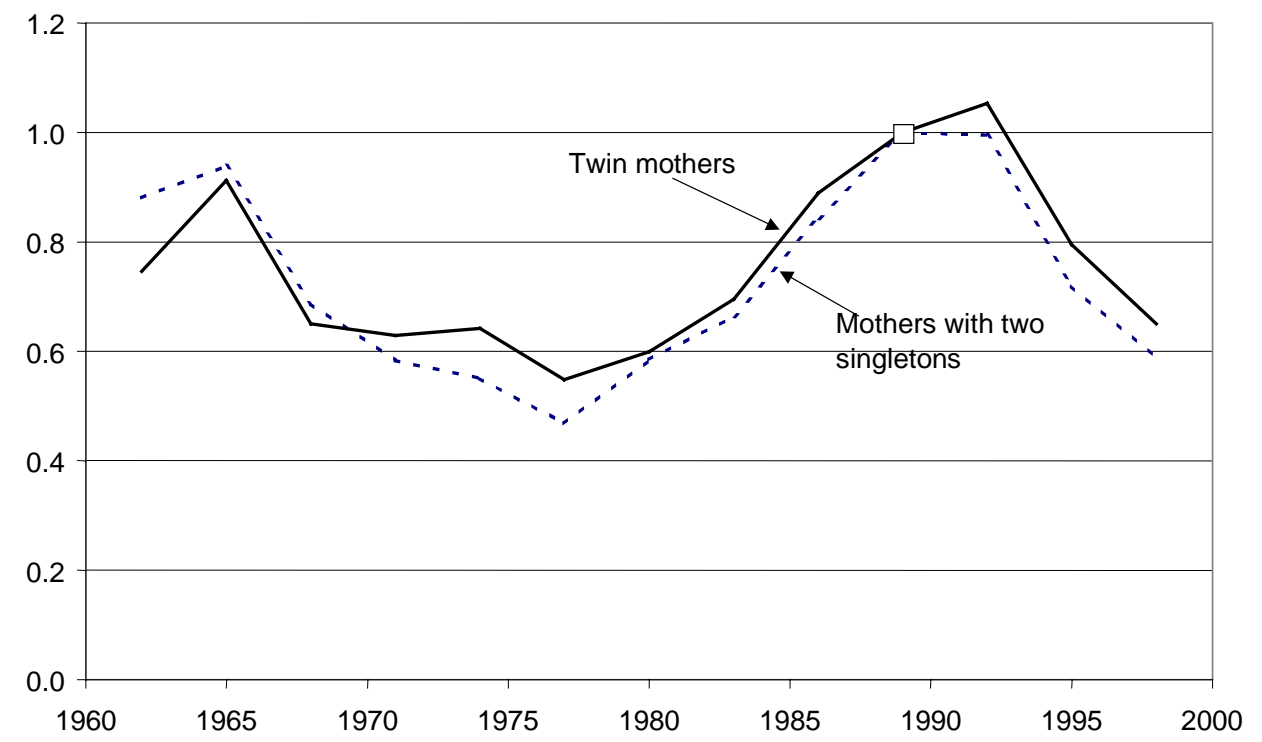

Note. Three-year calendar periods. Standardized for the mother's age at previous birth and for time since that birth.

Source: Table 4.

Figure 11. Next birth, by age of youngest child; relative risks for women with twins or two singletons respectively

2 years $=1$

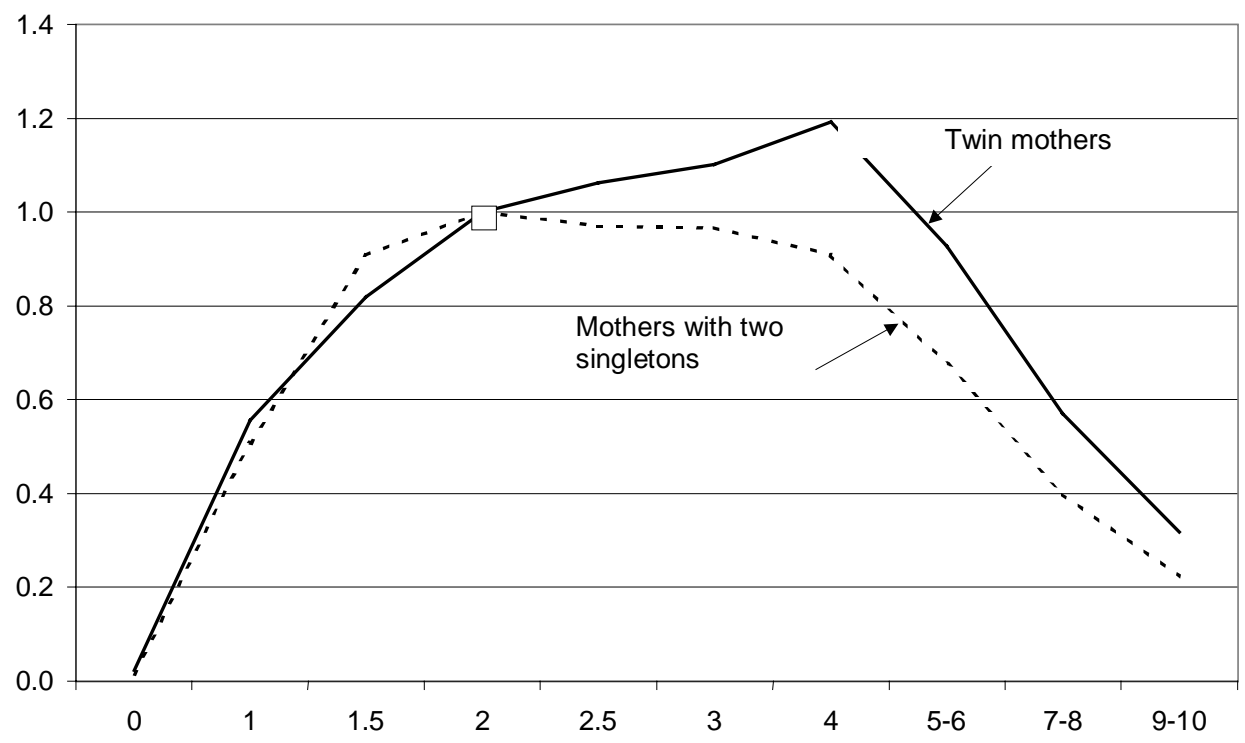

Age of

child

Note. Standardized for calendar period and for woman's age at previous birth.

Source: Table 4. 
Figure 12. Trend in third-birth intensities; risk for women with one twin pair followed by a singleton, relative to women with a singleton before twins

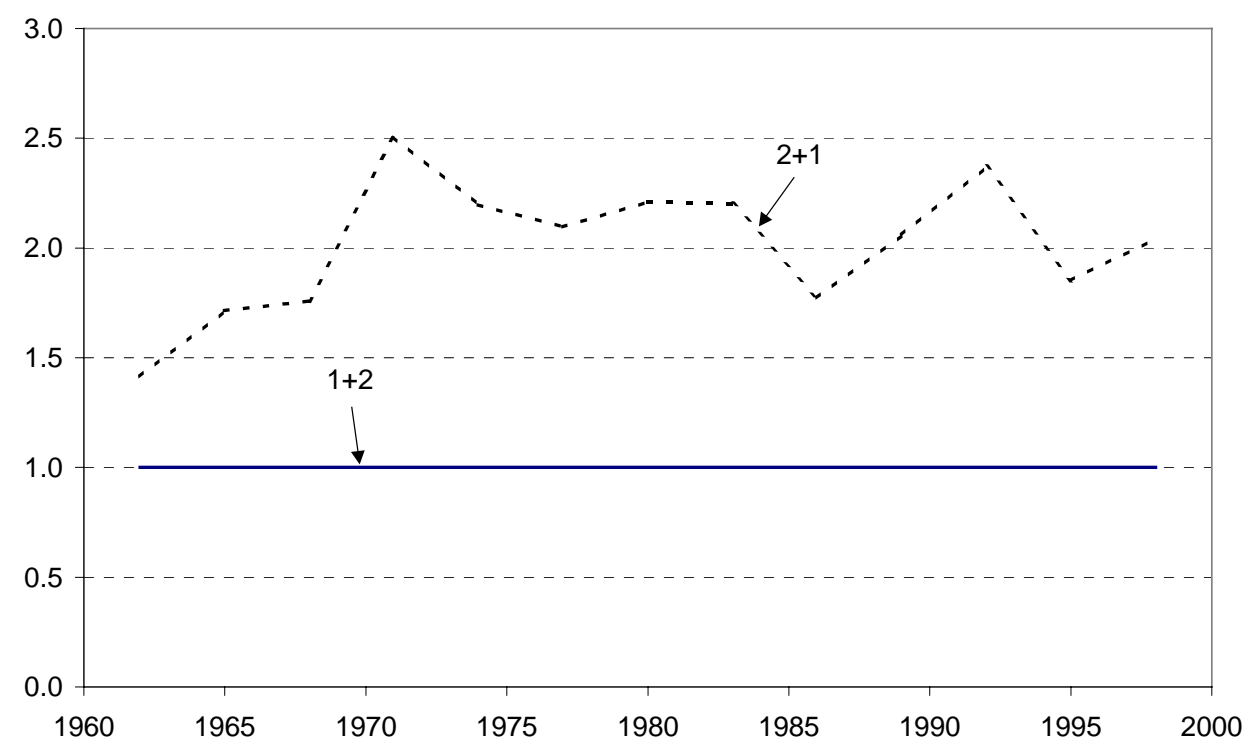

Note. Standardized for the woman's age at second birth and for time since that birth. Source: Table 5.

Figure 13 Third birth, by age of mother at second birth; risk for women with twins followed by a singleton, relative to women with a singleton before twins

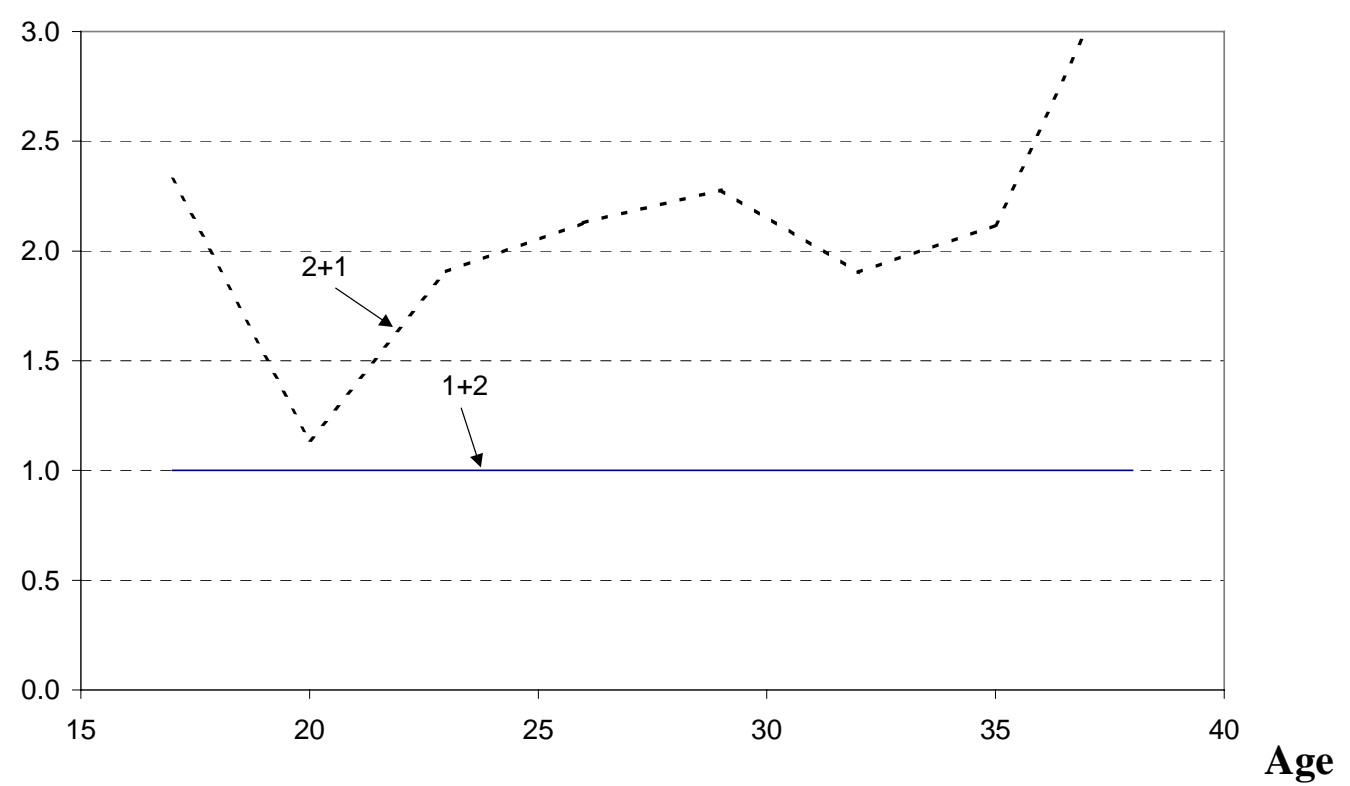

Note. Standardized for calendar period and time since last birth.

Source: Table 5. 
Figure 14. Third confinement, by time since second birth; risk for women with twins followed by a singleton, relative to women with a singleton before twins; by time since previous birth

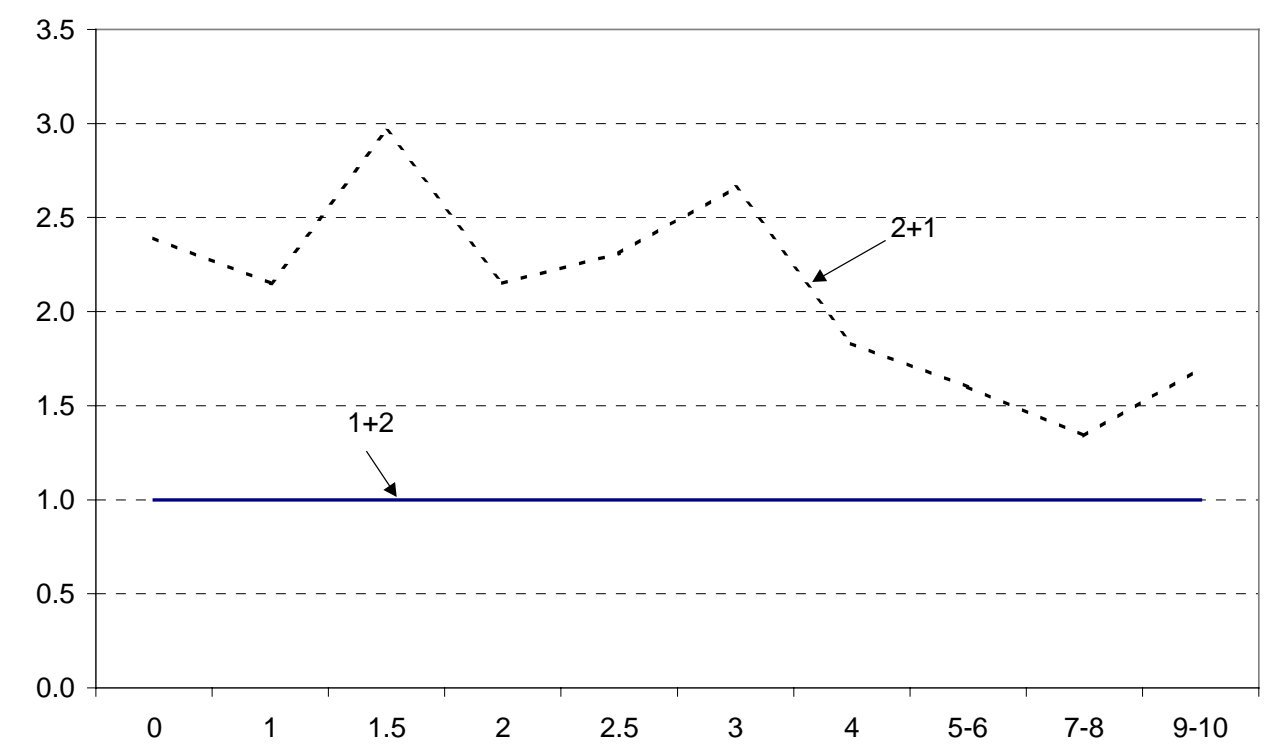

Note. Standardized for calendar period and for the woman's age at second confinement.

Source: Table 5.

Figure 15. Risk of a first twin birth, by order of birth, relative to the risk for a second-order birth; in selected calendar periods

Birth order $2=1$

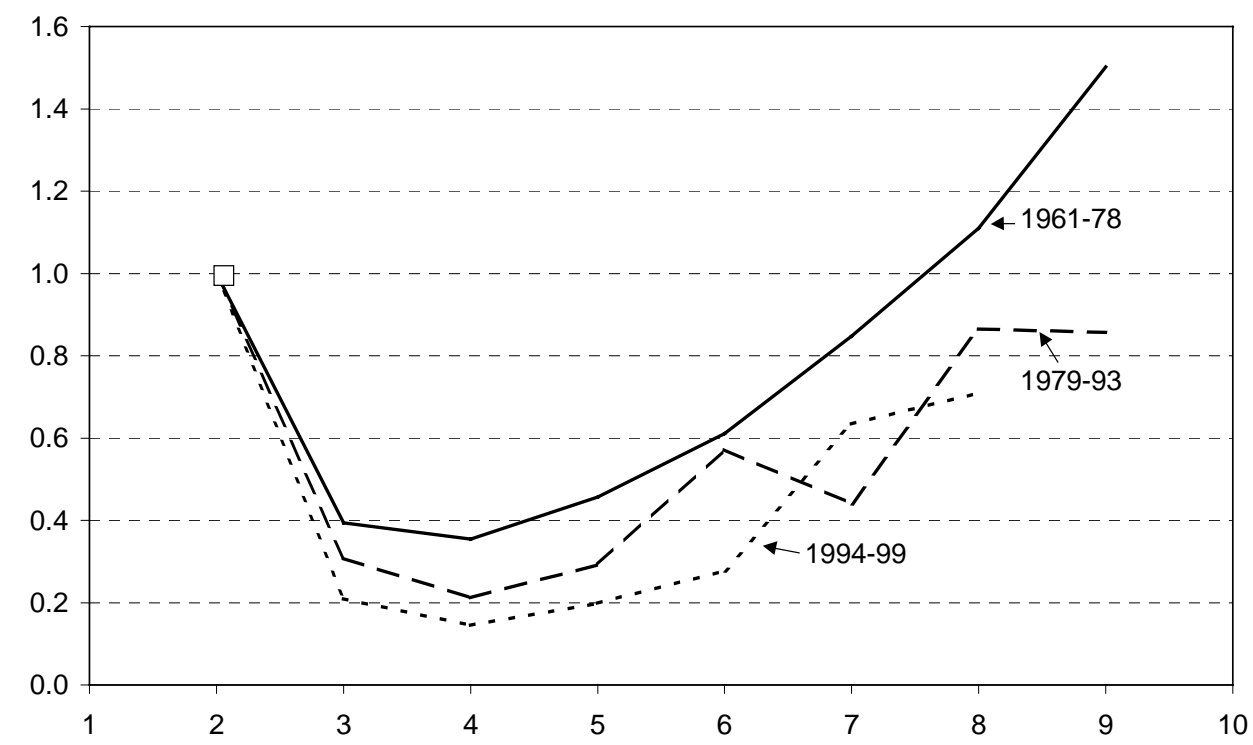

Note. Standardized for the woman's age at previous birth and time since that birth.

Source: Table 6. 
Figure 16. Risk of a first twin birth, by order of birth, relative to the risk for a second-order birth; for selected age groups at previous birth

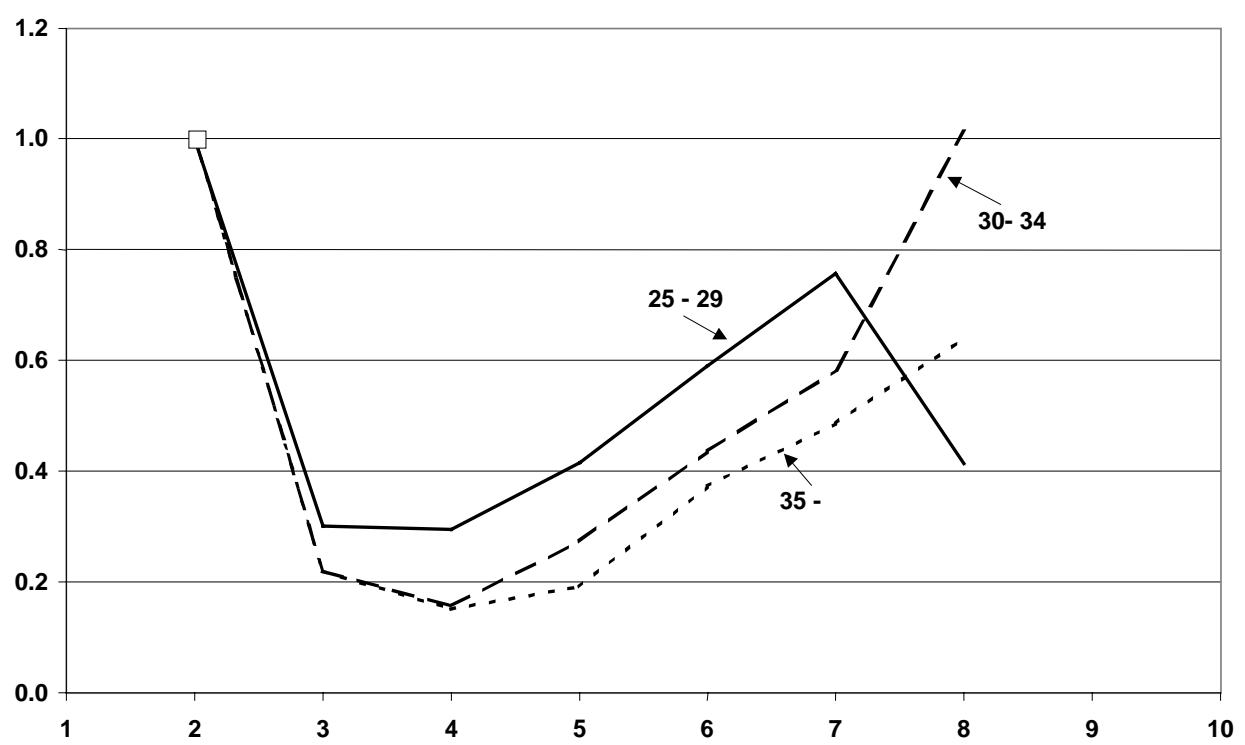

Note. Standardized for calendar period and for time since previous birth.

Birth order

Source: Table 6.

Figure 17. Risk of a first twin birth, by order of birth, relative to the risk for a second-order birth; for various ages of youngest child

Birth order $2=1$

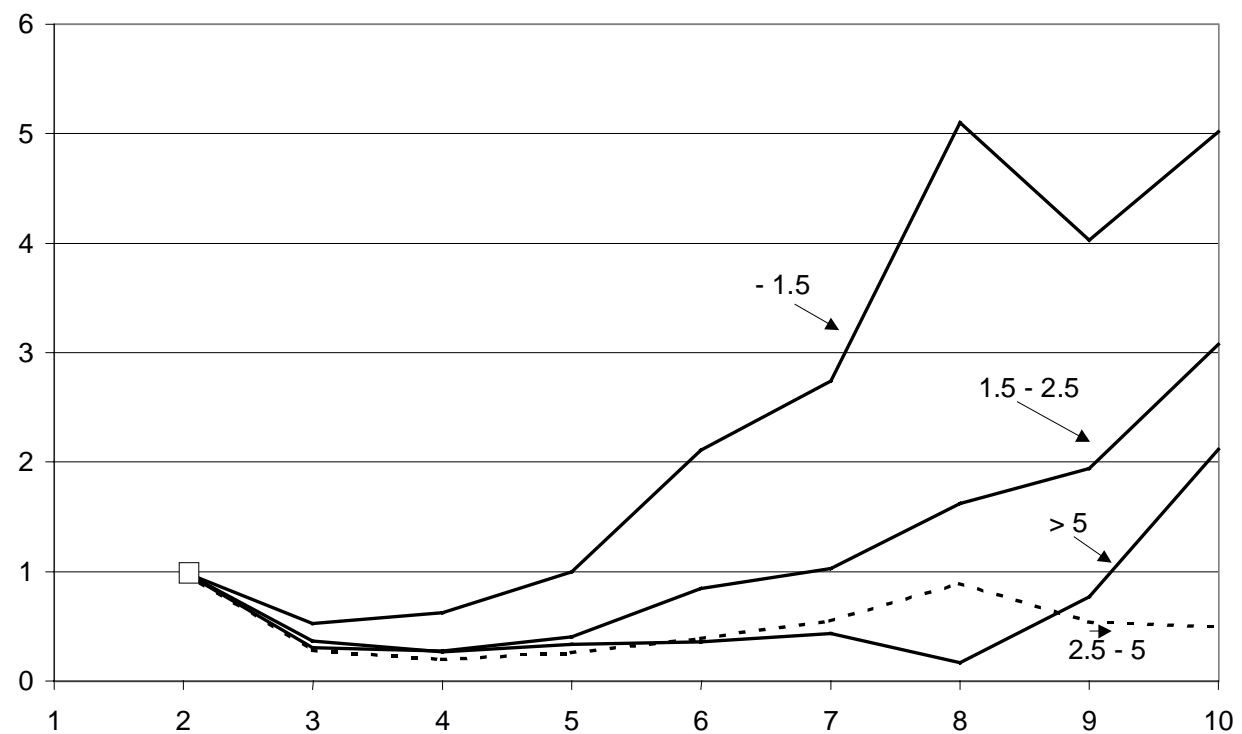

Birth order

Note. Standardized for calendar period and for the woman's age at previous birth. Source: Table 6. 